\title{
Role of NGF and its receptors in wound healing (Review)
}

\author{
ZHENXING LIU*, HAIWEI WU* and SHENGYUN HUANG \\ Department of Oral and Maxillofacial Surgery, Shandong Provincial Hospital, \\ Cheeloo College of Medicine, Shandong University, Jinan, Shandong 250021, P.R. China
}

Received November 16, 2020; Accepted March 8, 2021

DOI: $10.3892 /$ etm.2021.10031

\begin{abstract}
Wound healing is an important and complicated process that includes four highly integrated and overlapping phases, haemostasis, inflammation, proliferation and tissue remodelling. Nerve growth factor (NGF) was the first member of a family of neurotrophic factors to be discovered, and is an essential neurotrophic factor for the development and maintenance of the central and peripheral nervous systems. Several studies have proposed that NGF and its receptors, tropomyosin-related kinase receptor 1 and NGF receptor, are involved in the wound healing process, and are important components of the healing of several wounds both in vivo and in vitro. Topical application of NGF significantly promotes the healing of different types of wounds, including diabetic foot ulcers, pressure ulcers and corneal wounds. The present review summarizes the status of NGF and its receptors in current literature, and discusses data obtained in the last few years on the healing action of NGF in cutaneous, corneal and oral wounds.
\end{abstract}

\section{Contents}

1. Introduction

2. Biology of NGF and its receptors

3. Healing effects of NGF on different wounds

4. Conclusions

\section{Introduction}

Wound healing is a complex pathophysiological process involving different types of cells, cytokines and the

Correspondence to: Professor Shengyun Huang, Department of Oral and Maxillofacial Surgery, Shandong Provincial Hospital, Cheeloo College of Medicine, Shandong University, 324 Jingwuweiqi Road, Jinan, Shandong 250021, P.R. China

E-mail: huangsy28@sdu.edu.cn

${ }^{*}$ Contributed equally

Key words: nerve growth factor, tropomyosin-related kinase receptor 1 , nerve growth factor receptor, wound healing, skin, cornea, oral cavity extracellular matrix (1). Wound healing mainly consists of four highly integrated and overlapping phases, haemostasis, inflammation, proliferation and tissue remodelling $(1,2)$. Several endogenous and exogenous factors, such as growth factors, cytokines and chemokines, play important regulatory roles in each phase of wound healing (2-4). Increasing evidence suggest that neurotrophins, particularly nerve growth factor (NGF) and its receptors, play critical roles in the regulation of wound healing (5-8). In addition to its crucial role in the nervous system, NGF also exerts a wide range of effects in wound healing. For example, NGF promotes fibroblast and keratinocyte proliferation, extracellular matrix component expression and secretion, angiogenesis and myofibroblast differentiation (9-11). The topical application of NGF is considered a potential treatment strategy for promoting wound healing under pathological conditions, without obvious side effects (12-14). In addition, the Food and Drug Administration (FDA) has approved NGF eye drops for the treatment of rare neurotrophic keratitis (15). The present review discusses the role of NGF and its potential molecular mechanisms in wound healing in laboratory animal and clinical research.

\section{Biology of NGF and its receptors}

Biology of NGF. NGF is one of the most common neurotrophic factors that was first discovered by Rita Levi-Montalcini in the early 1950s $(16,17)$. NGF belongs to the neurotrophin (NT) family, which also includes brain-derived neurotrophic factor (BDNF), NT-3 and NT-4/5 (18). The gene encoding NGF is located on the proximal short arms of the first pair of chromosomes, 1p13.2. NGF is a high molecular weight complex that contains three subunits, $\alpha, \beta$ and $\gamma(19,20)$. The different subunits are bound together by non-covalent bonds, and there are also two $\mathrm{Zn}^{2+}$ ions that enhance the stability of the complex (21). Only the $\beta$-NGF subunit of NGF exhibits neurite-stimulating activity (21). This subunit is a dimer that is composed of two identical peptide chains that interact through non-covalent bonding, and each monomeric amino acid sequence contains 118 amino acid residues and three pairs of intramolecular disulfide bonds (22). The $\gamma$ subunit is a highly specific active protease, whereas the $\alpha$ subunit appears to have no significant activity (23).

NGF is synthesized in the endoplasmic reticulum in its prosomal form (proNGF) and is subsequently folded and transferred to the Golgi apparatus via the persistent secretory pathway or the regulated secretory pathway (24). proNGF 
is subsequently cleaved by the calcium-dependent serine protease, furin convertase, to expose the biologically active carboxyl terminus, thereby forming the $\beta$-NGF protein (24). In addition, some proNGF is directly released from cells, and mature $\beta$-NGF proteins are formed under the action of extracellular proteases $(23,25,26)$. NGF is predominantly secreted by nerve cells (23); however, some studies have reported that NGF can also be synthesized and secreted by non-neuronal cells, such as immune inflammatory cells, epithelial cells, keratinocytes, smooth muscle cells and fibroblasts (27-29).

NGF and proNGF are essential neurotrophic factors for the development and maintenance of the central and peripheral nervous systems $(30,31)$. In addition, NGF and proNGF play critical roles in the degeneration and repair events of neurological disorders, with different underlying aetiologies (32-34). An imbalance of NGF/proNGF is associated with early inflammation and neurodegeneration (35). Increasing evidence suggest that in addition to their neurotrophic functions, proNGF and NGF participate in several biological processes, including the immune response, inflammatory response, pulmonary hypertension, wound healing and cancer metastasis $(23,33,36-42)$. Studies on NGF and its receptors have identified novel therapeutic approaches for malignant tumors, diabetes, chronic wounds and cardiovascular diseases $(13,40)$.

Biology of NGF receptors. NGF exerts its biological functions through the activation of the high-affinity tropomyosin-related kinase receptor 1 (NTRK1) and the low-affinity nerve growth factor receptor (NGFR), which collaborate in mediating signaling (43-45) (Fig. 1).

NTRK1 receptor. NTRK1, also known as Trk-A, TRKA, MTC, TRK, TRK1 and p140-TrkA, is a 140-kDa transmembrane glycoprotein that belong to the receptor tyrosine kinase family and is encoded by a gene located on chromosome 1p23.1 (21,46). NTRK1 consists of three domains, an extracellular receptor domain, a single transmembrane helix and an intracellular tyrosine kinase domain (47). The NTRK1 extracellular sequence, which exhibits intrinsic tyrosine kinase activity, is composed of five distinct domains (D1-D5) (48). D1 and D3 contain cysteine-rich repetitive motifs, D2 contains three leucine-rich repeat domains, D4 and D5 are immunoglobulin-like domains, and D5 is responsible for NGF binding $(48,49)$. In the nervous system, NTRK1 is primarily expressed in cholinergic neurons that are implicated in spatial learning and memory, such as the central cortical pyramid, basal forebrain, striatum, compartment and lateral geniculate body, as well as in peripheral sensory neurons and sympathetic nerves (50). However, NTRK1 is also extensively expressed in non-neuronal tissues, including immune cells, tumor cells and stem cells, suggesting pleiotropic functions outside the nervous system $(51,52)$.

NGF binds to the D5 extracellular domain of NTRK1, resulting in dimerization of NTRK1 and activation of its intracellular kinase (48). A total of six tyrosine residues in the intracellular tyrosine kinase domain, namely, Tyr670, Tyr674, Tyr675, Tyr490, Tyr751 and Tyr785, are phosphorylated (53). Autophosphorylation of Tyr490, Tyr751 and Tyr785 results in activation of the three main downstream signal transduction pathways, the mitogen-activated protein kinase/extracellular signal-regulated protein kinase (MAPK/ERK) signaling pathway, the phosphatidylinositol-3-kinase/serine protein kinase (PI3K/Akt) signaling pathway and the phospholipase C- $\gamma$ (PLC- $\gamma)$ signaling pathway $(53,54)$. Most NGF-mediated biological activities, including the proliferation, survival and differentiation of neuronal cells, are due to the ligand-dependent NTRK1 activation of several signal transduction cascades $(32,33)$. NGF-NTRK1 activation has been reported to have several clinically relevant biological effects on non-neuronal cells, including promoting the survival, proliferation, metastasis and invasion of tumor cells (55-57).

NGFR receptor. NGFR, also known as $7^{5 \mathrm{NTR}}, \mathrm{CD} 271$, tumor necrosis factor receptor (TNFR)SF16 and Gp80-LNGFR, is a $75-\mathrm{kDa}$ highly conserved transmembrane glycoprotein that belongs to the TNFR superfamily and is encoded by a gene located on chromosome 17q21.33 $(58,59)$. NGFR consists of three domains, an extracellular receptor domain, a unique transmembrane helix and an intracellular tyrosine kinase domain (60). The extracellular sequence of NGFR contains four cysteine-rich (CR) sequence regions (CR1-CR4) that are responsible for binding to neurotrophic factors, with a nanomolar affinity, and binding to proneurotrophins (60-62). The intracellular domain of NGFR contains a potential TNFR-associated factor (TRAF)-binding region and Fas antigen (also called the death domain), which regulates apoptotic signals (60-62). In addition to the central and peripheral nervous systems, NGFR is also extensively distributed in several tissue systems throughout the body, such as epithelial, mesenchymal, lymphoid haematopoietic and tumor tissues (63).

The common neurotrophin receptor, NGFR, binds to NGF and all other neurotrophins, including BDNF, NT-3 and NT-4/5, with similar affinity and an extremely fast dissociation rate $(44,64)$. The binding of NGF to NGFR is a specific electrostatic interaction between polar amino acid residues, and two specific sites play important roles in this interaction, site I is composed of the CR1-CR2 junction and the CR2 domain, while site II is composed of the CR3-CR4 junction $(65,66)$. NGFR activation involves different molecular mechanisms in different types of cells and tissue environments, and active NGFR participates in regulating fundamental biological processes, such as cell survival, proliferation, attachment, migration, differentiation and apoptosis, via the nuclear transcription factor-kappa B, Jun N-terminal kinase (JNK), and ceramide signaling pathways (67-70). Although NGFR is a low-affinity NGFR, it may also participate in NGF high-affinity binding by interacting with the NTRK1 receptor to induce the growth and survival of neurites $(54,69,71)$. Activation of NGFR by proNGF induces the activation of apoptotic signaling pathways, involving the co-receptor, sortilin (72-74). In addition, NGFR is involved in the regulation of several physiological functions, and cooperates with Nogo-R, LINGO-1, A $\beta$, viral glycoprotein and tetanus toxin (75).

\section{Healing effects of NGF on different wounds}

Cutaneous wound healing. When damage causes a loss of skin integrity, the body immediately initiates the skin repair process to restore its integrity and maintain its function (1). Cutaneous 


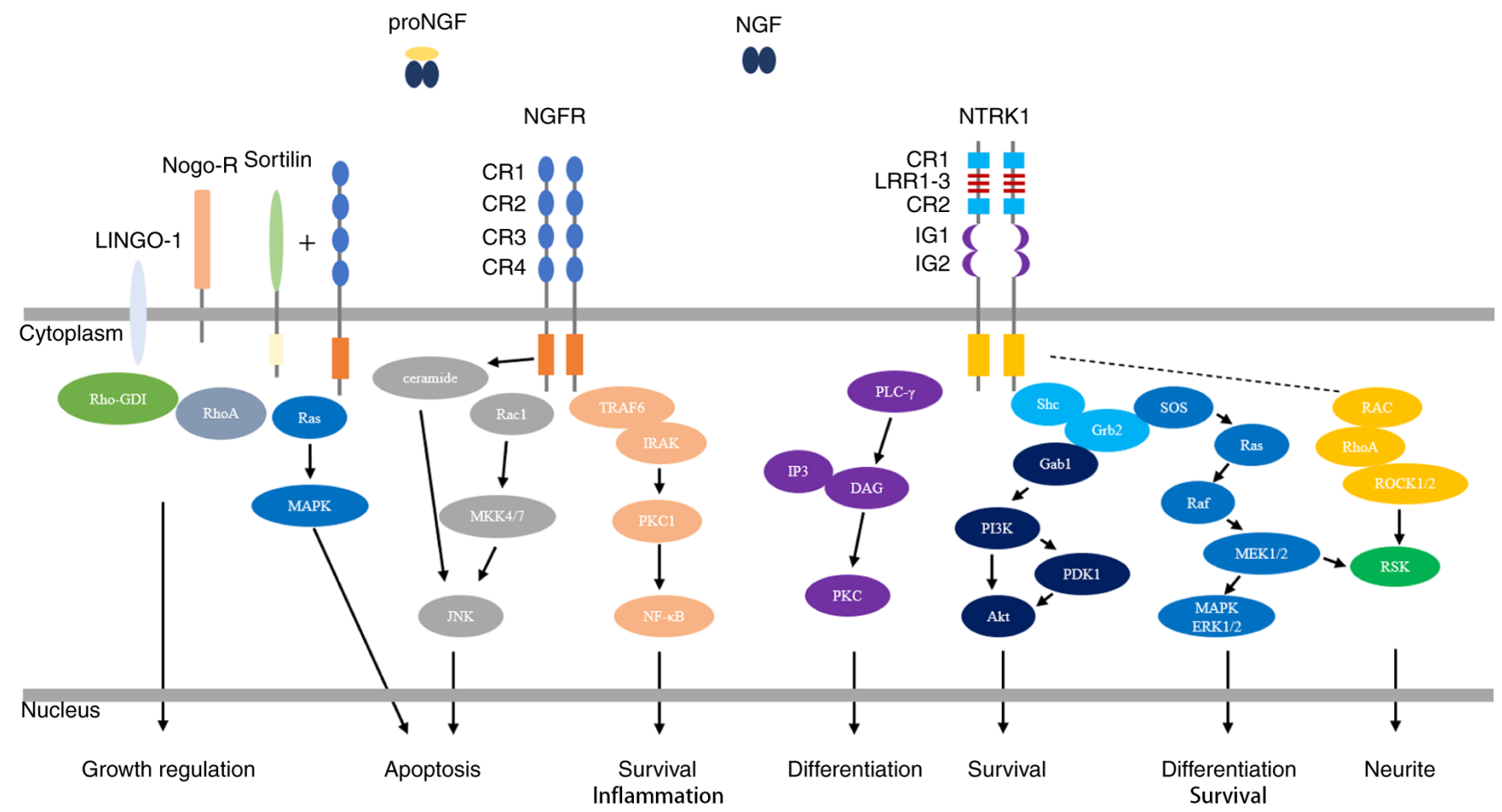

Figure 1. NGF-mediated regulation of the NGFR and NTRK1 signaling pathways. NGF binds to the extracellular domain of NTRK1 with high affinity, resulting in dimerization of NTRK1 and activation of its intracellular kinase. NTRK1 signaling is best characterized by activation of the three main downstream signal transduction pathways, the MAPK/ERK, PI3K/Akt and PLC- $\gamma$ signaling pathways, which results in the differentiation and survival of neurites. NGF binds to NGFR with low affinity. NGFR activation involves different molecular mechanisms in different types of cells and tissue environments, and exerts effects via the NF- $\mathrm{kB}$, JNK and ceramide signaling pathways, resulting in apoptosis, survival and inflammation. Interactions of NGFR with sortilin allow the high-affinity binding of proNGF. Subsequent activation of the Ras/MAPK pathway results in apoptosis. Interactions of NGFR with Nogo-R and LINGO-1 play roles in the regulation of growth. Activation of RhoA by the displacement of Rho-GDI inhibits neurite outgrowth from postnatal sensory neurons and cerebellar neurons. NGF, nerve growth factor; NTRK1, tropomyosin-related kinase receptor 1; MAPK/ERK, mitogen-activated protein kinase/extracellular signal-regulated protein kinase; PI3K/Akt, phosphatidylinositol-3-kinase/serine protein kinase; PLC- $\gamma$, phospholipase C- $\gamma$; NF- $\mathrm{B}$, nuclear transcription factor-kappa B; JNK, Jun N-terminal kinase; CR, cysteine-rich; Nogo-R, Nogo receptor; LINGO-1, leucine-rich repeat and immunoglobulin-like domain-containing protein-1.

wound healing is a complex pathophysiological process involving different types of cells (immune cells, keratinocytes, fibroblasts and vascular endothelial cells), cytokines (fibroblast growth factor, platelet-derived growth factor, transforming growth factor, epidermal growth factor, vascular endothelial growth factor and NGF) and signaling pathways $(38,76)$. The normal wound healing process is divided into four overlapping phases, haemostasis, inflammation, proliferation and tissue remodelling (2). Any disruptions in these processes can lead to wound healing disorders, such as chronic nonhealing ulcers or keloids (77).

Under physiological conditions, NGF is sustainably expressed in skin tissue by different types of cells, including keratinocytes, fibroblasts and mast cells, which is essential for maintaining skin homeostasis (78-81) (Table I). NTRK1 and NGFR are extensively expressed on the surfaces of different types of cells in the skin, including keratinocytes, melanocytes, fibroblasts and mast cells (82-86). Matsuda et al (87) reported that full-thickness skin wounds made in normal mice significantly increase NGF expression levels in the sera and wounded skin tissues of the mice. In addition, NGF mRNA and NGF have been detected in newly formed epithelial cells at wound edges and fibroblasts, which is consistent with the granulation tissue produced in the wound spaces (87). Previous studies have demonstrated that NGF is stored in the submandibular glands of mice, and sialoadenectomy prior to wounding inhibits serum NGF levels and delays the skin wound healing process $(87,88)$. Taken together, these findings suggest that NGF may play an important role in wound healing.

Topical application of NGF to wounds significantly promotes the healing of different types of wounds, including diabetic foot ulcers, pressure ulcers and nonhealing surgical wounds $(87,89,90)$. Preliminary experimental animal studies have reported that NGF expression significantly decreases in diabetic wounds and wound tissues following radiation treatment compared with normal skin wounds $(91,92)$. Generini et al (12) treated three diabetic patients with leg or foot ulcers that were unresponsive to conventional therapies with topical application of NGF, and the results demonstrated that NGF promoted healing after $5 \pm 14$ weeks of treatment. Even chronic ulcers with damage extending below the hypodermis and muscle layers healed in a few weeks following treatment with NGF, and the size of the ulcers significantly decreased for the first time after 8 weeks of NGF administration (32). Topical NGF also exerts a healing effect on human pressure ulcers $(93,94)$. A randomized clinical trial of 36 patients demonstrated that topical application of murine NGF significantly accelerated the healing of pressure ulcers compared with traditional treatment (94). Cutaneous ulcers secondary to vasculitis in patients with rheumatoid arthritis (RA) are extremely difficult to heal (95). A total of four patients with RA-associated skin ulcers were treated with 
Table I. Sources and role of nerve growth factor in wound healing.

\begin{tabular}{|c|c|c|c|}
\hline Type of wound & Cellular sources & Main function & Refs. \\
\hline Cutaneous & $\begin{array}{l}\text { Keratinocytes, } \\
\text { fibroblasts, mast } \\
\text { cells }\end{array}$ & $\begin{array}{l}\text { Inflammation response } \\
\text { Re-epithelialization } \\
\text { Keratinocyte proliferation } \\
\text { Epidermal stem cell proliferation, } \\
\text { differentiation and migration } \\
\text { Angiogenesis } \\
\text { Fibroplasia } \\
\text { Wound contraction } \\
\text { Myofibroblast differentiation } \\
\text { Collagen maturation and remodeling } \\
\text { Peripheral nerve regeneration }\end{array}$ & $\begin{array}{l}(11,75-78,93-95 \\
97-100)\end{array}$ \\
\hline Corneal & $\begin{array}{l}\text { Corneal } \\
\text { epithelial cells }\end{array}$ & $\begin{array}{l}\text { Inflammation response } \\
\text { Re-epithelialization } \\
\text { Corneal epithelial cell proliferation, } \\
\text { survival and migration } \\
\text { Fibroplasia } \\
\text { Myofibroblast differentiation } \\
\text { Peripheral nerve regeneration } \\
\text { Corneal sensitivity } \\
\text { Tear function }\end{array}$ & $\begin{array}{l}(102,104,106, \\
109-111)\end{array}$ \\
\hline Oral & $\begin{array}{l}\text { Keratinocytes, } \\
\text { fibroblasts, } \\
\text { leukocytes, } \\
\text { salivary ductal } \\
\text { cells }\end{array}$ & $\begin{array}{l}\text { Inflammation response } \\
\text { Re-epithelialization } \\
\text { Oral epithelial cell proliferation } \\
\text { Fibroplasia } \\
\text { Myofibroblast differentiation } \\
\text { Collagen maturation and remodeling }\end{array}$ & $(114-116,118-122)$ \\
\hline
\end{tabular}

topical NGF, and the symptoms of pain and inflammation were significantly relieved after 2-3 weeks (96). The ulcers progressively improved and were completely healed after 8 weeks (96). Notably, intraperitoneal and topical applications of NGF increase the survival rate and may increase wound healing and promote survival in irradiated animals (92).

The molecular mechanisms underlying NGF-induced cutaneous wound healing are not yet fully understood. However, studies have reported that NGF participates in several biological activities during the healing process via complex molecular mechanisms (Table I). In the skin, NGF is predominantly synthesized and released by keratinocytes (97). Different types of cells express NGF receptors, including keratinocytes, melanocytes, fibroblasts and mast cells (98). Skin injury can increase the secretion of neurotrophic factors by peripheral nerve endings (97). Among these factors, substance $\mathrm{P}$ and neurokinin A directly induce NGF mRNA expression and NGF secretion in keratinocytes $(99,100)$. Conversely, NGF can increase the secretion of neurotrophic factors, including calcitonin gene-related peptide, by peripheral nerve endings, thereby regulating the immune inflammatory response associated with the wound healing process $(101,102)$. NGF significantly stimulates the proliferation of normal human keratinocytes in a dose-dependent manner (79). NGF plays a functional role in reparative neovascularization via a VEGF-Akt-NO-mediated mechanism (103). NGF accelerates wound healing by promoting wound re-epithelialization, which partly relies on accelerated dermal fibroblast migration via activation of the PI3K/Akt-Rac1-JNK and ERK signaling pathways (7). In wound granulation tissue, NGF can also induce myofibroblast differentiation and collagen synthesis via the NGFR-F-actin-MRTF-A signaling pathway, and induce wound contraction and extracellular matrix remodelling $(9,97)$. In addition, NGFR promotes the healing of skin burn wounds by improving the potential of epidermal stem cells to differentiate, proliferate and migrate (104).

Corneal wound healing. The cornea is the transparent outer layer of the eye that serves as a protective barrier (105). Damage to the corneal epithelium caused by scratches or surgery is common (106). Corneal wound healing is an exceedingly complex process involving the coordination of cellular activities stimulated and regulated by several growth factors that reach the wound through tears and limbic vessels (107). Delays in corneal wound healing results in keratinization of the corneal epithelium and corneal opacity (108).

NGF is extensively expressed in normal human and rat corneal tissues and is predominantly produced by corneal epithelial cells (109) (Table I). In addition, NTRK1 and NGFR are widely expressed in corneal epithelial cells, endothelial 
cells, stromal cells, limbal stem cells and conjunctival epithelial cells (110). Ocular surface damage and inflammation can increase NGF levels $(109,111)$. A transient increase in corneal NGF levels is observed following corneal epithelial injury in vivo (109). Inhibition of endogenous NGF activity by neutralizing anti-NGF antibodies delays the corneal epithelial healing rate, whereas administration of exogenous NGF accelerates healing (109). Lambiase et al (111) reported that plasma NGF levels are significantly higher in patients with vernal keratoconjunctivitis compared with controls, which is associated with higher inflammatory cell numbers in the conjunctival tissue of vernal keratoconjunctivitis. Given the positive effect of NGF in promoting corneal healing, the FDA has approved NGF eye drops for the treatment of rare neurotrophic keratitis (15). Cellini et al (112) observed complete wound healing in patients treated with NGF eye drops, and the stromal incision was not visible when assessed via optical coherence tomography on day 21 .

The epithelium needs to be reconstructed during corneal healing, and this process mainly relies on the proliferation and migration of adjacent corneal epithelial cells $(105,106)$. During corneal wound healing, NGF plays a major role in promoting cell survival and migration by binding to the NTRK1 receptor, which is mediated by both the upregulation of matrix metalloproteinase- 9 and the cleavage of $\beta 4$ integrin $(47,113,114)$. In addition, NGF promotes the healing of corneal stroma and endothelial cells $(109,110)$. The role of NGF in corneal angiogenesis remains controversial; however, NGF can facilitate innervations of perivascular nerves to regulate blood flow in neovessels $(10,115,116)$. In addition, it has been demonstrated that topical application of exogenous NGF can promote corneal healing by increasing corneal sensitivity and improving tear function in patients with neurotrophic keratitis (117).

Oral wound healing. Oral injuries are very common and usually caused by trauma, surgery, periodontal treatment and radiation therapy (118). Improper treatment can cause severe complications, which can affect breathing, language articulation, chewing and swallowing (119). Oral wound healing is rapid and results in little scar formation compared with cutaneous wound healing (120). Recent studies have suggested that the reduced scar formation in oral mucosa is associated with fibroblast phenotypes, oral bacteria, saliva and the moist environment of the oral cavity $(118,121)$.

NGF is extensively expressed and synthesized by oral keratinocytes, fibroblasts, infiltrating inflammatory leukocytes and salivary ductal cells, and can be secreted into saliva (122-124) (Table I). The main form of NGF in saliva is proNGF, which can be further converted by enzymes released at the site of activity (123). In addition, NGF receptors are also expressed in oral tissues. NTRK1 is predominantly expressed in mucosal basal cells, salivary duct epithelial cells and gingival epithelial cells, while NGFR is only expressed in mucosal basal cell layers and salivary duct epithe$\operatorname{lium}(123,124)$.

Recent studies have reported that NGF and proNGF are involved in oral wound healing (Table I). When the oral mucosa is wounded, NGF and proNGF in the saliva can reach NGF receptors on keratinocytes and fibroblasts that were previously hidden by oral epithelial layers (125). Plasmin generated by keratinocytes at wound sites can cleave pro-NGF to form mature NGF (126). Mature NGF can access NTRK1 on the basal keratinocytes of the wound edges, thereby enhancing the proliferation and migration of keratinocytes (124). NGF can upregulate the expression levels of E-cadherin and zona occludens-1 in mucosal epithelial cells, suggesting that NGF may contribute to re-establishing mucosal epithelial barrier function (127). Infiltrating inflammatory cells in the epithelium and the connective tissue of the oral mucosa express NGF and NGF receptors $(128,129)$. Proinflammatory cytokines released after tissue damage promote NGF synthesis, while NGF enhances superoxide production via neutrophils (128). Fibroblasts and myofibroblasts that appear during wound healing synthesize and secrete NGF and express NGF receptors (130). NGF induces the differentiation of fibroblasts into myofibroblasts, which are responsible for both tissue contraction and extracellular matrix component secretion (131). Thus, NGFR mediates the apoptosis of myofibroblasts in the late stages of healing, and decreases collagen deposition and scar formation $(122,123,125)$.

\section{Conclusions}

Wound healing is a complex process involving different types of cells, tissues, cytokines, chemokines and growth factors in each phase. Understanding its physiology will provide more mechanism-based therapeutic alternatives for the treatment of different types of wounds. Previous studies have demonstrated the vital roles of NGF in the regulation of wound healing. The present study summarized the biology of NGF and its receptors (NTRK1 and NGFR), and recent studies have revealed the involvement of NGF and its receptors in different types of wound healing. NGF and its receptors exert several biological effects on the process of wound healing, including participation in epithelial cell and fibroblast migration, inflammatory immune response regulation, angiogenesis, myofibroblast differentiation and tissue remodelling. Notably, topical application of exogenous NGF exerts a significant healing effect on cutaneous, corneal and oral wounds, without obvious side effects. This healing action is also applicable to some wounds that fail to respond to conventional treatment. However, further studies are required to determine the underlying molecular mechanisms by which NGF and its receptors participate in wound healing processes. In addition, more randomized controlled trials are required to assess whether topical application of high concentrations of NGF can be used to treat different types of wounds.

\section{Acknowledgements}

Not applicable.

\section{Funding}

The present review was supported by the Postdoctoral Innovation Project of Shandong Province (grant no. 202002050).

\section{Availability of data and materials}

Not applicable. 


\section{Authors' contributions}

SH conceived the present review and designed its framework. ZL and $\mathrm{HW}$ performed the literature review and drafted the initial manuscript. ZL and HW edited the manuscript. Data sharing is not applicable. All authors have read and approved the final manuscript.

\section{Ethics approval and consent to participate}

Not applicable.

\section{Patient consent for publication}

Not applicable.

\section{Competing interests}

The authors declare that they have no competing interests.

\section{References}

1. Wang PH, Huang BS, Horng HC, Yeh CC and Chen YJ: Wound healing. J Chin Med Assoc 81: 94-101, 2018.

2. Ridiandries A, Tan JTM and Bursill CA: The role of chemokines in Wound healing. Int J Mol Sci 19: 3217, 2018

3. Yasukawa K, Okuno T and Yokomizo T: Eicosanoids in skin Wound healing. Int J Mol Sci 21: 8435, 2020.

4. Zarei F and Soleimaninejad M: Role of growth factors and biomaterials in wound healing. Artif Cells Nanomed Biotechnol 46 906-911, 2018

5. Gostynska N, Pannella M, Rocco ML, Giardino L, Aloe L and Calza L: The pleiotropic molecule NGF regulates the in vitro properties of fibroblasts, keratinocytes, and endothelial cells: Implications for wound healing. Am J Physiol Cell Physiol 318: C360-C371, 2020

6. Lambiase A, Manni L, Bonini S, Rama P and Aloe L: Nerve growth factor promotes corneal healing: Structural, biochemical, and molecular analyses of rat and human corneas. Invest Ophthalmol Vis Sci 41: 1063-1069, 2000.

7. Chen JC, Lin BB, Hu HW, Lin C, Jin WY, Zhang FB, Zhu YA, Lu CJ, Wei XJ and Chen RJ: NGF accelerates cutaneous wound healing by promoting the migration of dermal fibroblasts via the PI3K/Akt-Rac1-JNK and ERK pathways. Biomed Res Int 2014 547187, 2014

8. Ishikawa S, Takeda A, Akimoto M, Kounoike N, Uchinuma E and Uezono Y: Effects of neuropeptides and their local administration to cutaneous wounds in sensory-impaired areas. J Plast Surg Hand Surg 48: 143-147, 2014.

9. Liu Z, Cao Y, Liu G, Yin S, Ma J, Liu J, Zhang M and Wang Y: p75 neurotrophin receptor regulates NGF-induced myofibroblast differentiation and collagen synthesis through MRTF-A. Exp Cell Res 383: 111504, 2019.

10. Troullinaki M, Alexaki VI, Mitroulis I, Witt A, Klotzschevon Ameln A, Chung KJ, Chavakis T and Economopoulou M: Nerve growth factor regulates endothelial cell survival and pathological retinal angiogenesis. J Cell Mol Med 23: 2362-2371, 2019

11. Tanigawa T, Ahluwalia A, Watanabe T, Arakawa T and Tarnawski AS: Nerve growth factor injected into the gastric ulcer base incorporates into endothelial, neuronal, glial and epithelial cells: Implications for angiogenesis, mucosal regeneration and ulcer healing. J Physiol Pharmacol 66: 617-621, 2015.

12. Generini S, Tuveri MA, Matucci Cerinic M, Mastinu F, Manni L and Aloe L: Topical application of nerve growth factor in human diabetic foot ulcers. A study of three cases. Exp Clin Endocrinol Diabetes 112: 542-544, 2004

13. Aloe L, Tirassa P and Lambiase A: The topical application of nerve growth factor as a pharmacological tool for human corneal and skin ulcers. Pharmacol Res 57: 253-258, 2008.

14. Cheret J,Lebonvallet N, Carre JL, Misery Land Le Gall-Ianotto C: Role of neuropeptides, neurotrophins, and neurohormones in skin wound healing. Wound Repair Regen 21: 772-788, 2013.
15. Kanu LN and Ciolino JB: Nerve growth factor as an ocular therapy: Applications, challenges, and future directions. Semin Ophthalmol: 1-8, 2021 (Epub ahead of print). doi: 10.1080/0882 0538.2021 .1890793 .

16. Levi-Montalcini R and Angeletti PU: Nerve growth factor. Physiol Rev 48: 534-569, 1968.

17. Levi-Montalcini R: The nerve growth factor 35 years later. Science 237: 1154-1162, 1987.

18. Sun HL and Jiang T: The structure of nerve growth factor in complex with lysophosphatidylinositol. Acta Crystallogr F Struct Biol Commun 71: 906-912, 2015.

19. Varon S, Nomura J and Shooter EM: The isolation of the mouse nerve growth factor protein in a high molecular weight form. Biochemistry 6: 2202-2209, 1967.

20. Smith AP, Varon S and Shooter EM: Multiple forms of the nerve growth factor protein and its subunits. Biochemistry 7 : 3259-3268, 1968.

21. Wiesmann C and de Vos AM: Nerve growth factor: Structure and function. Cell Mol Life Sci 58: 748-759, 2001

22. Angeletti RH and Bradshaw RA: Nerve growth factor from mouse submaxillary gland: Amino acid sequence. Proc Natl Acad Sci USA 68: 2417-2420, 1971.

23. Sofroniew MV, Howe CL and Mobley WC: Nerve growth factor signaling, neuroprotection, and neural repair. Annu Rev Neurosci 24: 1217-1281, 2001.

24. Seidah NG, Benjannet S, Pareek S, Savaria D, Hamelin J, Goulet B, Laliberte J, Lazure C, Chrétien M and Murphy RA: Cellular processing of the nerve growth factor precursor by the mammalian pro-protein convertases. Biochem J 314: 951-960, 1996.

25. Levi-Montalcini R, Skaper SD, Dal Toso R, Petrelli L and Leon A: Nerve growth factor: From neurotrophin to neurokine. Trends Neurosci 19: 514-520, 1996.

26. Lewin GR and Barde YA: Physiology of the neurotrophins. Ann Rev Neurosci 19: 289-317, 1996.

27. Micera A, Puxeddu I, Aloe L and Levi-Schaffer F: New insights on the involvement of Nerve Growth Factor in allergic inflammation and fibrosis. Cytokine Growth Factor Rev 14: 369-374, 2003.

28. Micera A, Lambiase A, Aloe L, Bonini S, Levi-Schaffer F and Bonini S: Nerve growth factor involvement in the visual system: Implications in allergic and neurodegenerative diseases. Cytokine Growth Factor Rev 15: 411-417, 2004.

29. Lambiase A, Micera A, Sgrulletta R, Bonini S and Bonini S: Nerve growth factor and the immune system: Old and new concepts in the cross-talk between immune and resident cells during pathophysiological conditions. Curr Opin Allergy Clin Immunol 4: 425-430, 2004

30. Hondermarck H: Neurotrophins and their receptors in breast cancer. Cytokine Growth Factor Rev 23: 357-365, 2012.

31. Dahlström M, Nordvall G, Sundström E, Åkesson E, Tegerstedt G, Eriksdotter $\mathrm{M}$ and Forsell $\mathrm{P}$ : Identification of amino acid residues of nerve growth factor important for neurite outgrowth in human dorsal root ganglion neurons. Eur J Neurosci 50: 3487-3501, 2019.

32. Rocco ML, Soligo M, Manni L and Aloe L: Nerve growth factor: Early studies and recent clinical trials. Curr Neuropharmacol 16: $1455-1465,2018$

33. Aloe L, Rocco ML, Balzamino BO and Micera A: Nerve growth factor: Role in growth, differentiation and controlling cancer cell development. J Exp Clin Cancer Res 35: 116, 2016.

34. Skaper SD: Nerve growth factor: A neuroimmune crosstalk mediator for all seasons. Immunology 151: 1-15, 2017.

35. Capsoni S, Brandi R, Arisi I, D'Onofrio M and Cattaneo A: A dual mechanism linking NGF/proNGF imbalance and early inflammation to Alzheimer's disease neurodegeneration in the AD11 anti-NGF mouse model. CNS Neurol Disord Drug Targets 10: 635-647, 2011.

36. Bracci-Laudiero L and De Stefano ME: NGF in early embryogenesis, differentiation, and pathology in the nervous and immune systems. In: Neurotoxin Modeling of Brain Disorders-Life-long Outcomes in Behavioral Teratology. pp125-152, 2015.

37. Niederhauser O, Mangold M, Schubenel R, Kusznir EA, Schmidt D and Hertel C: NGF ligand alters NGF signaling via p75(NTR) and TrkA. J Neurosci Res 61: 263-272, 2000.

38. Kawamoto $\mathrm{K}$ and Matsuda $\mathrm{H}$ : Nerve growth factor and wound healing. In: NGF and Related Molecules in Health and Disease. pp369-384, 2004. 
39. Tomellini E, Touil Y, Lagadec C, Julien S, Ostyn P, Ziental-Gelus N, Meignan S, Lengrand J, Adriaenssens E, Polakowska R and Le Bourhis X: Nerve growth factor and proNGF simultaneously promote symmetric self-renewal, quiescence, and epithelial to mesenchymal transition to enlarge the breast cancer stem cell compartment. Stem Cells 33: 342-353, 2015.

40. Steckiewicz KP, Barcińska E and Woźniak M: Nerve growth factor as an important possible component of novel therapy for cancer, diabetes and cardiovascular diseases. Cell Mol Biol (Noisy-le-Grand) 64: 16-23, 2018.

41. Rowe CW, Dill T, Faulkner S, Gedye C, Paul JW, Tolosa JM, Jones M, King S, Smith R and Hondermarck H: The precursor for nerve growth factor (proNGF) in thyroid cancer lymph node metastases: Correlation with primary tumour and pathological variables. Int J Mol Sci 20: 5924, 2019.

42. Rowe CW, Faulkner S, Paul JW, Tolosa JM, Gedye C, Bendinelli C, Wynne K, McGrath S, Attia J, Smith R and Hondermarck H: The precursor for nerve growth factor (proNGF) is not a serum or biopsy-rinse biomarker for thyroid cancer diagnosis. BMC Endocr Disord 19: 128, 2019.

43. Lad SP, Peterson DA, Bradshaw RA and Neet KE: Individual and combined effects of TrkA and p75NTR nerve growth factor receptors. A role for the high affinity receptor site. J Biol Chem 278: 24808-24817, 2003.

44. Meakin SO and Shooter EM: The nerve growth factor family of receptors. Trends Neurosci 15: 323-331, 1992.

45. Frade JM and Barde YA: Nerve growth factor: Two receptors, multiple functions. Bioessays 20: 137-145, 1998

46. Weier HU, Rhein AP, Shadravan F, Collins C and Polikoff D: Rapid physical mapping of the human trk protooncogene (NTRK1) to human chromosome 1q21-q22 by P1 clone selection, fluorescence in situ hybridization (FISH), and computer-assisted microscopy. Genomics 26: 390-393, 1995.

47. Barbacid M: Structural and functional properties of the TRK family of neurotrophin receptors. Ann N Y Acad Sci 766: 442-458, 1995

48. Wiesmann C, Ultsch MH, Bass SH and de Vos AM: Crystal structure of nerve growth factor in complex with the ligand-binding domain of the TrkA receptor. Nature 401: 184-188, 1999.

49. Urfer R, Tsoulfas P, O'Connell L, Hongo JA, Zhao W and Presta LG: High resolution mapping of the binding site of TrkA for nerve growth factor and TrkC for neurotrophin-3 on the second immunoglobulin-like domain of the Trk receptors. J Biol Chem 273: 5829-5840, 1998

50. Kassel O, de Blay F, Duvernelle C, Olgart C, Israel-Biet D, Krieger P, Moreau L, Muller C, Pauli G and Frossard N: Local increase in the number of mast cells and expression of nerve growth factor in the bronchus of asthmatic patients after repeated inhalation of allergen at low-dose. Clin Exp Allergy 31: 1432-1440, 2001

51. Zheng MG, Sui WY, He ZD, Liu Y, Huang YL, Mu SH, Xu XZ, Zhang JS, Qu JL, Zhang J, et al: TrkA regulates the regenerative capacity of bone marrow stromal stem cells in nerve grafts. Neural Regen Res 14: 1765-1771, 2019.

52. Zhang M, Zhang Y, Ding J, Li X, Zang C, Yin S, Ma J, Wang Y and Cao Y: The role of TrkA in the promoting wounding-healing effect of CD271 on epidermal stem cells. Arch Dermatol Res 310 737-750, 2018

53. Freund-Michel V and Frossard N: The nerve growth factor and its receptors in airway inflammatory diseases. Pharmacol Ther 117: 52-76, 2008 .

54. Reichardt LF: Neurotrophin-regulated signalling pathways. Philos Trans R Soc Lond B Biol Sci 361: 1545-1564, 2006.

55. Micera A, Lambiase A, Stampachiacchiere B, Bonini S, Bonini S and Levi-Schaffer F: Nerve growth factor and tissue repair remodeling: trkA(NGFR) and p75(NTR), two receptors one fate. Cytokine Growth Factor Rev 18: 245-256, 2007.

56. Faulkner S, Jobling P, Rowe CW, Rodrigues Oliveira SM, Roselli S, Thorne RF, Oldmeadow C, Attia J, Jiang CC, Zhang XD, et al: Neurotrophin receptors TrkA, p75 $5^{\mathrm{NTR}}$, and sortilin are increased and targetable in thyroid cancer. Am J Pathol 188: 229-241, 2018.

57. Bradshaw RA, Pundavela J, Biarc J, Chalkley RJ, Burlingame AL and Hondermarck H: NGF and ProNGF: Regulation of neuronal and neoplastic responses through receptor signaling. Adv Biol Regul 58: 16-27, 2015.

58. Huber LJ and Chao MV: A potential interaction of p75 and trkA NGF receptors revealed by affinity crosslinking and immunoprecipitation. J Neurosci Res 40: 557-563, 1995.
59. Huebner K, Isobe M, Chao M, Bothwell M, Ross AH, Finan J, Hoxie JA, Sehgal A, Buck CR, Lanahan A, et al: The nerve growth factor receptor gene is at human chromosome region 17q12-17q22, distal to the chromosome 17 breakpoint in acute leukemias. Proc Natl Acad Sci USA 83: 1403-1407, 1986.

60. Roux P: Neurotrophin signaling through the p75 neurotrophin receptor. Progress Neurobiol 67: 203-233, 2002.

61. Yan $\mathrm{H}$ and Chao MV: Disruption of cysteine-rich repeats of the p75 nerve growth factor receptor leads to loss of ligand binding. J Biol Chem 266: 12099-12104, 1991.

62. Baldwin AN, Bitler CM, Welcher AA and Shooter EM: Studies on the structure and binding properties of the cysteine-rich domain of rat low affinity nerve growth factor receptor (p75NGFR). J Biol Chem 267: 8352-8359, 1992.

63. Pincelli C: p75 neurotrophin receptor in the skin: Beyond its neurotrophic function. Front Med (Lausanne) 4: 22, 2017.

64. Chao MV, Bothwell MA, Ross AH, Koprowski H, Lanahan AA, Buck CR and Sehgal A: Gene transfer and molecular cloning of the human NGF receptor. Science 232: 518-521, 1986.

65. Shamovsky IL, Ross GM, Riopelle RJ and Weaver DF: The interaction of neurotrophins with the p75NTR common neurotrophin receptor: A comprehensive molecular modeling study. Protein Sci 8: 2223-2233, 1999.

66. He XL and Garcia KC: Structure of nerve growth factor complexed with the shared neurotrophin receptor p75. Science 304: 870-875, 2004.

67. Meeker R and Williams K: Dynamic nature of the p75 neurotrophin receptor in response to injury and disease. J Neuroimmune Pharmacol 9: 615-628, 2014.

68. Barker PA: p75NTR is positively promiscuous: Novel partners and new insights. Neuron 42: 529-533, 2004.

69. Chao MV: Neurotrophins and their receptors: A convergence point for many signalling pathways. Nat Rev Neurosci 4: 299-309, 2003

70. Teng HK, Teng KK, Lee R, Wright S, Tevar S, Almeida RD, Kermani P, Torkin R, Chen ZY, Lee FS, et al: ProBDNF induces neuronal apoptosis via activation of a receptor complex of p75NTR and sortilin. J Neurosci 25: 5455-5463, 2005.

71. Skaper SD: The neurotrophin family of neurotrophic factors: An overview. Methods Mol Biol 846: 1-12, 2012.

72. Lee R, Kermani P, Teng KK and Hempstead BL: Regulation of cell survival by secreted proneurotrophins. Science 294: 1945-1948, 2001

73. Beattie MS, Harrington AW, Lee R, Kim JY, Boyce SL, Longo FM, Bresnahan JC, Hempstead BL and Yoon SO: ProNGF induces p75-mediated death of oligodendrocytes following spinal cord injury. Neuron 36: 375-386, 2002.

74. Domeniconi M, Hempstead BL and Chao MV: Pro-NGF secreted by astrocytes promotes motor neuron cell death. Mol Cell Neurosci 34: 271-279, 2007.

75. Dechant G and Barde YA: The neurotrophin receptor p75(NTR): Novel functions and implications for diseases of the nervous system. Nat Neurosci 5: 1131-1136, 2002.

76. Roosterman D, Goerge T, Schneider SW, Bunnett NW and Steinhoff M: Neuronal control of skin function: The skin as a neuroimmunoendocrine organ. Physiol Rev 86: 1309-1379, 2006.

77. Sorg H, Tilkorn DJ, Hager S, Hauser J and Mirastschijski U: Skin wound healing: An update on the current knowledge and concepts. Eur Surg Res 58: 81-94, 2017.

78. Marconi A, Terracina M, Fila C, Franchi J, Bonté F, Romagnoli G, Maurelli R, Failla CM, Dumas M and Pincelli C: Expression and function of neurotrophins and their receptors in cultured human keratinocytes. J Invest Dermatol 121: $1515-1521,2003$

79. Pincelli C, Sevignani C, Manfredini R, Grande A, Fantini F, Bracci-Laudiero L, Aloe L, Ferrari S, Cossarizza A and Giannetti A: Expression and function of nerve growth factor and nerve growth factor receptor on cultured keratinocytes. J Invest Dermatol 103: 13-18, 1994

80. Murase K, Murakami Y, Takayanagi K, Furukawa Y and Hayashi K: Human fibroblast cells synthesize and secrete nerve growth factor in culture. Biochem Biophys Res Commun 184: 373-379, 1992.

81. Tron VA, Coughlin MD, Jang DE, Stanisz J and Sauder DN Expression and modulation of nerve growth factor in murine keratinocytes (PAM 212). J Clin Invest 85: 1085-1089, 1990.

82. Hefti F: Nerve growth factor promotes survival of septal cholinergic neurons after fimbrial transections. J Neurosci 6: $2155-2162,1986$ 
83. Hefti F, Dravid A and Hartikka J: Chronic intraventricular injections of nerve growth factor elevate hippocampal choline acetyltransferase activity in adult rats with partial septo-hippocampal lesions. Brain Res 293: 305-311, 1984.

84. Manni L, Rocco ML, Bianchi P, Soligo M, Guaragna M, Barbaro SP and Aloe L: Nerve growth factor: Basic studies and possible therapeutic applications. Growth Factors 31: 115-122, 2013.

85. Minnone G, De Benedetti F and Bracci-Laudiero L: NGF and its receptors in the regulation of inflammatory response. Int $\mathrm{J}$ Mol Sci 18: 1028, 2017.

86. Raychaudhuri SK, Raychaudhuri SP, Weltman H and Farber EM: Effect of nerve growth factor on endothelial cell biology: Proliferation and adherence molecule expression on human dermal microvascular endothelial cells. Arch Dermato Res 293: 291-295, 2001.

87. Matsuda H, Koyama H, Sato H, Sawada J, Itakura A, Tanaka A, Matsumoto M, Konno K, Ushio H and Matsuda K: Role of nerve growth factor in cutaneous wound healing: Accelerating effects in normal and healing-impaired diabetic mice. J Exp Med 187: 297-306, 1998.

88.Li AK, Koroly MJ, Schattenkerk ME, Malt RA and Young M: Nerve growth factor: Acceleration of the rate of wound healing in mice. Proc Natl Acad Sci USA 77: 4379-4381, 1980.

89. Nakagaki O, Miyoshi H, Sawada T, Atsumi T, Kondo T and Atsumi T: Epalrestat improves diabetic wound healing via increased expression of nerve growth factor. Exp Clin Endocrinol Diabetes 121: 84-89, 2013.

90. Ali Bahar M, Bauer B, Tredget EE and Ghahary A: Dermal fibroblasts from different layers of human skin are heterogeneous in expression of collagenase and types I and III procollagen mRNA. Wound Repair Regen 12: 175-182, 2004.

91. AnandP,TerenghiG,WarnerG,KopelmanP,Williams-ChestnutRE and Sinicropi DV: The role of endogenous nerve growth factor in human diabetic neuropathy. Nat Med 2: 703-707, 1996.

92. Shi CM, Qu JF and Cheng TM: Effects of the nerve growth factor on the survival and wound healing in mice with combined radiation and wound injury. J Radiat Res 44: 223-228, 2003

93. Bernabei R, Landi F, Bonini S, Onder G, Lambiase A, Pola R and Aloe L: Effect of topical application of nerve-growth factor on pressure ulcers. Lancet 354: 307, 1999.

94. Landi F, Aloe L, Russo A, Cesari M, Onder G, Bonini S, Carbonin PU and Bernabei R: Topical treatment of pressure ulcers with nerve growth factor: A randomized clinical trial. Ann Intern Med 139: 635-641, 2003.

95. Coelho S, Amarelo M, Ryan S, Reddy M and Sibbald RG: Rheumatoid arthritis-associated inflammatory leg ulcers: A new treatment for recalcitrant wounds. Int Wound J 1: 81-84, 2004.

96. Tuveri M, Generini S, Matucci-Cerinic M and Aloe L: NGF, a useful tool in the treatment of chronic vasculitic ulcers in rheumatoid arthritis. Lancet 356: 1739-1740, 2000.

97. Ashrafi M, Baguneid M and Bayat A: The role of neuromediators and innervation in cutaneous wound healing. Acta Derm Venereol 96: 587-594, 2016.

98. Aloe L, Tirassa P and Bracci-Laudiero L: Nerve growth factor in neurological and non-neurological diseases: Basic findings and emerging pharmacological prospectives. Curr Pharm Des 7 : $113-123,2001$

99. Burbach GJ, Kim KH, Zivony AS, Kim A, Aranda J, Wright S, Naik SM, Caughman SW, Ansel JC and Armstrong CA: The neurosensory tachykinins substance $\mathrm{P}$ and neurokinin A directly induce keratinocyte nerve growth factor. J Invest Dermatol 117: 1075-1082, 2001.

100.Gibran NS, Tamura R, Tsou R and Isik FF: Human dermal microvascular endothelial cells produce nerve growth factor: Implications for wound repair. Shock 19: 127-130, 2003.

101. Bowles WR, Sabino M, Harding-Rose C and Hargreaves KM Chronic nerve growth factor administration increases the peripheral exocytotic activity of capsaicin-sensitive cutaneous neurons. Neurosci Lett 403: 305-308, 2006.

102. Banks BEC, Vernon CA and Warner JA: Nerve growth factor has anti-inflammatory activity in the rat hindpaw oedema test. Neurosci Lett 47: 41-45, 1984

103. Emanueli C, Salis MB, Pinna A, Graiani G, Manni L and Madeddu P: Nerve growth factor promotes angiogenesis and arteriogenesis in ischemic hindlimbs. Circulation 106: $2257-2262,2002$
104. Zhang M, Cao Y, Li X, Hu L, Taieb SK, Zhu X, Zhang J, Feng Y, Zhao R, Wang M, et al: Cd271 mediates proliferation and differentiation of epidermal stem cells to support cutaneous burn wound healing. Cell Tissue Res 371: 273-282, 2018.

105. Wilson SE: Corneal wound healing. Exp Eye Res 197: 108089, 2020.

106. Spadea L, Giammaria D and Trabucco P: Corneal wound healing after laser vision correction. Br J Ophthalmol 100 28-33, 2016

107. Wilson SE, Mohan RR, Mohan RR, Ambrósio R, Hong J and Lee J: The corneal wound healing response. Progress Retinal Eye Res 20: 625-637, 2001.

108. Agrawal VB and Tsai RJ: Corneal epithelial wound healing. Indian J Ophthalmol 51: 5-15, 2003.

109. Lambiase A, Manni L, Bonini S, Rama P and Aloe L: Nerve growth factor promotes corneal healing: Structural, biochemical, and molecular analyses of rat and human corneas. Invest Ophthalmol Vis Sci 41: 1063-1069, 2000.

110. You L, Kruse FE and Völcker HE: Neurotrophic factors in the human cornea. Invest Ophthalmol Vis Sci 41: 692-702, 2000 .

111. Lambiase A, Bonini S, Micera A, Magrini L and Aloe L: Increased plasma levels of nerve growth factor in vernal keratoconjunctivitis and relationship to conjunctival mast cells. Invest Ophthalmol Vis Sci 36: 2127-2132, 1995.

112. Cellini M, Bendo E, Bravetti GO and Campos EC: The use of nerve growth factor in surgical wound healing of the cornea. Ophthalmic Res 38: 177-181, 2006.

113. Blanco-Mezquita T, Martinez-Garcia C, Proenca R, Zieske JD, Bonini S, Lambiase A and Merayo-Lloves J: Nerve growth factor promotes corneal epithelial migration by enhancing expression of matrix metalloprotease-9. Invest Ophthalmol Vis Sci 54: 3880-3890, 2013

114. Touhami A, Grueterich M and Tseng SC: The role of NGF signaling in human limbal epithelium expanded by amniotic membrane culture. Invest Ophthalmol Vis Sci 43: 987-994, 2002.

115. Matsuyama A, Takatori S, Sone Y, Ochi E, Goda M, Zamami Y, Hashikawa-Hobara N, Kitamura Y and Kawasaki H: Effect of nerve growth factor on innervation of perivascular nerves in neovasculatures of mouse cornea. Biol Pharm Bull 40: 396-401, 2017.

116. Seo K, Choi J, Park M and Rhee C: Angiogenesis effects of nerve growth factor (NGF) on rat corneas. J Vet Sci 2: 125-130, 2001.

117. Lambiase A, Sacchetti M and Bonini S: Nerve growth factor therapy for corneal disease. Curr Opin Ophthalmol 23: 296-302, 2012.

118. Larjava H: Oral Wound Healing: An Overview. John Wiley \& Sons, Ltd, 2013.

119. Nauta A, Gurtner G and Longaker MT: Wound healing and regenerative strategies. Oral Dis 17: 541-549, 2011

120. Chin GS, Kim WJ, Lee TY, Liu W, Saadeh PB, Lee S, Levinson H, Gittes GK and Longaker MT: Differential expression of receptor tyrosine kinases and Shc in fetal and adult rat fibroblasts: Toward defining scarless versus scarring fibroblast phenotypes. Plast Reconstr Surg 105: 972-979, 2000.

121. Chen L, Arbieva ZH, Guo S, Marucha PT, Mustoe TA and DiPietro LA: Positional differences in the wound transcriptome of skin and oral mucosa. BMC Genomics 11: 471, 2010

122. Hayashi K, Karatsaidis A, Schreurs O, Bjornland T, Sugisaki M and Schenck K: NGF and its receptors TrkA and p75NTR in the epithelium of oral lichen. J Oral Pathol Med 37: 241-248, 2008

123. Naesse EP, Schreurs O, Messelt E, Hayashi K and Schenck K: Distribution of nerve growth factor, pro-nerve growth factor, and their receptors in human salivary glands. Eur J Oral Sci 121: 13-20, 2013

124. Hayashi K, Storesund T, Schreurs O, Khuu C, Husvik C, Karatsaidis A, Helgeland K, Martin-Zanca D and Schenck K Nerve growth factor beta/pro-nerve growth factor and their receptors in normal human oral mucosa. Eur J Oral Sci 115: 344-354, 2007.

125. Schenck K, Schreurs O, Hayashi K and Helgeland K: The role of nerve growth factor (NGF) and its precursor forms in ora wound healing. Int J Mol Sci 18: 386, 2017.

126. Bruno MA and Cuello AC: Activity-dependent release of precursor nerve growth factor, conversion to mature nerve growth factor, and its degradation by a protease cascade. Proc Natl Acad Sci USA 103: 6735-6740, 2006. 
127. Tan L, Hatzirodos $\mathrm{N}$ and Wormald PJ: Effect of nerve growth factor and keratinocyte growth factor on wound healing of the sinus mucosa. Wound Repair Regen 16: 108-116, 2008

128. Bonini S, Rasi G, Bracci-Laudiero ML, Procoli A and Aloe L: Nerve growth factor: Neurotrophin or cytokine? Int Arch Allergy Immunol 131: 80-84, 2003.

129. Samah B, Porcheray F and Gras G: Neurotrophins modulate monocyte chemotaxis without affecting macrophage function. Clin Exp Immunol 151: 476-486, 2008.

130. Palazzo E, Marconi A, Truzzi F, Dallaglio K, Petrachi T, Humbert P, Schnebert S, Perrier E, Dumas M and Pincelli C: Role of neurotrophins on dermal fibroblast survival and differentiation. J Cell Physiol 227: 1017-1025, 2012.
131. Darby IA, Zakuan N, Billet F and Desmouliere A: The myofibroblast, a key cell in normal and pathological tissue repair. Cell Mol Life Sci 73: 1145-1157, 2016.

This work is licensed under a Creative Commons Attribution-NonCommercial-NoDerivatives 4.0 International (CC BY-NC-ND 4.0) License. 